3. Dobrokhotov, B. (1974) Double bass : history and methodology. Moscow : Music, 334 [in Russian].

4. Interview with Krzysztof Penderecki // Dominanta. Kharkov. 2010. Vol. 7, 12-14 [in Russian].

5. Kogoutek, Ts. (1976) Technique of composition in the music of the XX century. Moscow, 358 [in Russian].

6. Kokoreva, L. (1997) Musical culture of Poland of the twentieth century : Karol Szymanowski, Witold Lutoslavsky, Krzysztof Penderetsky. Essays. Moscow: Moscow State Conservatory, 161 [in Russian].

7. Rakov, L.V. (2004) History of double bass art. Moscow : Composer, 222 [in Russian].

8. Kholopov, Yu. N. (2005) Harmony. Practical course. Part 2. Moscow, 624 [in Russian].

9. Kholopova, V.N. (1999) Forms of musical works. St. Petersburg, 496 [in Russian].

УДК 78.071

DOI https://doi.org/10.31723/2524-0447-2020-30-1-22

Юрий Николаевич Бучка

ORCID: 0000-0003-1013-6000

приват-доцент кафедры сольного пения

Одесской национальной музыкальной академии имени А. В. Неждановой

yury.buchka@gmail.com

\title{
ПРЕЕМСТВЕННОСТЬ ИСПОЛНИТЕЛЬСКИХ ТРАДИЦИЙ Е. ИВАНОВА - В. НАВРОТСКОГО В ИНТЕРПРЕТАЦИИ ВОКАЛЬНОГО ЦИКЛА М. МУСОРГСКОГО «ПЕСНИ И ПЛЯСКИ СМЕРТИ»
}

Цель работы - рассмотреть преемственность ценнейших исполнительских традиций Одесской вокальной школы, выявить особенности педагогических инноваций, гипотез, экстраполяций и педагогических доминаций в исполнении вокального иикла «Песни и пляски смерти» М. Мусоргского. Методологию исследования составляет применение системного, исторического и компаративного подходов. Научная новизна работы заключается в выявлении преемственности и экстраполяций (аутентичного переноса и адаптации в педагогическом опыте) педагогических принципов Е. Иванова и вокально-методической системы В. Навротского (на примере иикла «Песни и пляски смерти» М. Мусоргского). Выводы. В современной практике Одесской вокальной школы сохраняется преемственность важнейших исполнительских и педагогических принципов. Основные принципы обучения, заложенные E. Ивановым, сохраняются и составляют истоки профессионализма и исполнительского интеллекта B. Навротского. Особенный интерес представляет самобытная интерпретация В. Навротским вокального иикла «Песни и пляски смерти» М. Мусоргского. Одной из важнейших дидактических задач указанного произведения становится формирование в единой совокупности профессиональных навыков, а также образно-содержательных и эмоционально-художественных задач музыкального текста. В философской трактовке смерти В. Навротский предлагает исполнителю не создать фантастикотрагедийный в своей жуткой реальности образ, а попытаться представить смерть разрушением духовного гомеостаза (Парацельс), разрушением состояния гармонии между Внутренним и Внешним мирами, приблизить этот образ к человеческому бытию, как бы «тонко упростить». Многогранность исполнительских и педагогических подходов в интерпретации вокального цикла «Песни и пляски смерти» М. Мусоргского способствует целостному формированию сложных образов этого произведения.

Ключевые слова: преемственность, исполнительские традиции, Одесская вокальная школа, Е. Иванов, В. Навротский, М. Мусоргский, «Песни и пляски смерти».

Бучка Юрій Миколайович, приват-доцент кафедри сольного співу Одеської національної музичної академії імені А. В. Нежданової

Спадкоємність виконавських традицій Є. Іванова - В. Навротського в інтерпретації вокального циклу «Пісні і танці смерті» М. Мусоргського

Мета роботи - розглянути спадкоємність найцінніших виконавських традицій Одеської вокальноі школи, виявити особливості педагогічних інновацій, гіпотез, екстраполяцій і педагогічних домінацій у виконанні вокального циклу «Пісні і танці смерті» М. Мусоргського. Методологію дослідження становить застосування системного, історичного та компаративного підходів. Наукова новизна роботи полягає у виявленні спадкоємності й екстраполяції (автентичного перенесення й адаптації в педагогічному досвіді) педагогічних принципів $Е$. Іванова та вокально-методичної системи В. Навротського 
(на прикладі циклу «Пісні і танці смерті» М. Мусоргського). Висновки. У сучасній практиці Одеської вокальної школи зберігається спадкоємність найважливіших виконавських $і$ педагогічних принципів. Основні приниипи навчання, закладені С. Івановим, зберігаються і становлять витоки професіоналізму та виконавської інтелекту В. Навротського. Особливий інтерес становить самобутня інтерпретація B. Навротським вокального ииклу «Пісні і танці смерті» М. Мусоргського. Одним із найважливіших дидактичних завдань вказаного твору стає формування в єдиній сукупності професійних навичок, а такожк образно-змістових і емоційно-художсніх завдань музичного тексту. У філософському трактуванні смерті В. Навротський пропонує виконавцю не створити фантастико-трагедійний у своїй страшній реальності образ, а спробувати уявити смерть руйнуванням духовного гомеостазу (Парацельс), руйнуванням стану гармонії між Внутрішнім і Зовнішнім світами, наблизити ией образ до людського буття, ніби «тонко спростити». Багатогранність виконавських та педагогічних підходів в інтерпретації вокального циклу «Пісні і танці смерті» М. Мусоргського сприяє иілісному формуванню складних образів цього твору.

Ключові слова: спадкоємність, виконавські традицї, Одеська вокальна школа, С. Іванов, В. Навротський, М. Мусоргський, «Пісні і танці смерті».

Buchka Yury Nykolaevych, Associate Professor at the Department of the Solo Singing of the Odessa National A. V. Nezhdanova Academy of Music

The continuity of the performing traditions of $E$. Ivanov - V. Navrotsky in the interpretation of the vocal cycle "Songs and Dances of Death" by M. Mussorgsky

Research objective is to consider the continuity of the most valuable performers as followers of the Odessa vocal school traditions, to identify the features of pedagogical innovations, hypotheses, extrapolations and pedagogical dominances, performing the vocal cycle "Songs and Dances of Death" by M. Mussorgsky. These methodological analyzes based on applying a systematic, historical and comparative approaches. The scientific novelty of the research is to identify the continuity and extrapolation (authentic transfer and adaptation in the pedagogical experience) of the pedagogical principles of E. Ivanov and the vocal-methodical system of V. Navrotsky (on the example of the cycle "Songs and Dances of Death" by M. Mussorgsky). Conclusions. There is a continuity of the most important performing and pedagogical principles in modern practice of the Odessa vocal school. The basic principles of training, laid down by E. Ivanov, are preserved and constitute the origins of V. Navrotsky's professionalism and performing intellect. The original interpretation of the vocal cycle "Songs and Dances of Death" by V. Navrotsky is of particular interest. One of the most important didactic tasks of this work is the formation of a single set of professional skills, as well as figuratively-meaningful and emotional-artistic tasks of a musical text. In the philosophical interpretation of death, $V$. Navrotsky proposes to the performer not to create a fantastic and tragic image in his creepy reality, but try to imagine death as the destruction of spiritual homeostasis (Paracelsus), the destruction of the state of harmony between the Inner and Outer Worlds, to bring this image closer to human being, as if "to simplify subtly". The versatility of performing and pedagogical approaches in interpreting the vocal cycle "Songs and Dances of Death" by M. Mussorgsky contributes to the holistic formation of complex images of this research.

Key words: continuity, performing traditions, Odessa Vocal School, E. Ivanov, V. Navrotsky, M. Mussorgsky, "Songs and Dances of Death".

Актуальность темы исследования. Методология научного познания, в частности в сфере высшего музыкального образования, теоретическое и практическое обоснование основных направлений развития современного научного знания, исполнительской и педагогической деятельности, безусловно, подчеркивает актуальность осмысления ценнейших традиций, изучения опыта старшего поколения отечественных музыкантов, его роли в культурном пространстве настоящего времени, где все увеличивающийся поток информации синергетически сочетается с принципами системности, нелинейности образования, индивидуализации и интернационализации.

Многолетние традиции зарождения и колоссального развития имеет такой уникальный исполнительско-педагогический феномен, как Одесская вокальная школа. Изучение педагогической и исполнительской деятельности корифеев и столпов Одесской вокальной школы - А. Неждановой, О. Благовидовой, Е. Иванова, Н. Огренича, Г. Поливановой становится актуальной исследовательской областью в музыковедческой литературе [1, с. 3]. В настоящее время мы наблюдаем, как уже третье поколение замечательных музыкантов обобщает и обогащает бесценный многолетний педагогический и исполнительский опыт кафедры сольного пения, достигая значительных результатов. К их числу принадлежит Василий Всеволодович Навротский, чья творческая и педагогическая деятельность продолжает принципы вокального мастерства его Учителя - Евгения Николаевича Иванова. Погрузиться в их харизматичный тандем воспоминаний, записей педагога и его известного ученика, получить их уникальные навыки вокального мастерства нам довелось во время обучения в ассистентуре-стажировке (в классе профессора В. Навротского). 
Цель исследования - рассмотрение ценнейших исполнительских традиций, педагогических инноваций, гипотез, экстраполяций и педагогических доминаций в исполнении вокального цикла «Песни и пляски смерти» М. Мусоргского.

Научная новизна - впервые анализируется проявление преемственности и экстраполяций (аутентичного переноса и адаптации в педагогическом опыте) педагогических принципов Е. Иванова и вокально-методической системы В. Навротского (на примере вокального цикла «Песни и пляски смерти» М. Мусоргского).

Изложение основного материала. Апеллируя к концепции исполнительского мастерства, оригинальности и самобытности исполнительской манеры представителей Одесской вокальной школы, следует акцентировать, что ее основу составили уникальные постулаты, прививаемые с первых ступеней обучения, специфический вокально-технический арсенал определенных профессиональных средств и навыков, (например, уникальных аналитико-стилевых), которые на протяжении многих лет прививались не одному поколению исполнителей. Как исполнительский феномен Одесская вокальная школа представляет собой сложную систему, состоящую из совокупности исполнительских (технических) приемов и навыков, принципов интерпретации музыкального текста, где существенным является вокальное и общемузыкальное наследство, где кропотливо и тщательно формируют творческую индивидуальность, соотнося с воспитанием высокого уровня общей культуры и морально-духовных качеств молодых музыкантов.

Первые представители вокального искусства в Одессе опирались на итальянскую традицию, принципы belcanto, что составило прочный фундамент Одесской вокальной школы. Воспитание певца, которому в равной степени доступно исполнение протяженных кантиленных мелодий и ярких виртуозных украшений, который обладает значительным диапазоном голоса и умеет петь в разных «манерах», который свободно владеет различными исполнительскими нюансами, составляет суть того, что является основной целью педагогов Одесской вокальной школы. Попытаемся подтвердить наши утверждения яркими примерами из истории вокальной кафедры и Одесской национальной музыкальной академии имени А. В. Неждановой.

Одним из первых педагогов по классу вокала в Одесском музыкальном училище был знаменитый итальянский баритон поколения рубежа XIX-XX вв. Доменико Джованни Баттиста Дельфино Менотти. Долгие годы он с успехом пел в итальянской опере, в 1883 г. исполнял партию Симона Бокканегры Дж. Верди, в 1885 г. участвовал в премьере третьей редакции оперы-балета «Вилли» Дж. Пуччини. После ухода с большой сцены певец обосновался в Одессе и, как отмечает Т. Руффо, «стал во главе вокальной школы, пользуясь всеобщей любовью и уважением» [6, с. 12]. Д. Дельфино Менотти считается одним из первых педагогов, приглашенных на вокальное отделение Одесской консерватории первым ректором Витольдом Осиповичем Малишевским.

В контексте об итальянских истоках и корнях Одесской вокальной школы хотелось бы упомянуть Камилло Эверарди. Камилло Эверарди (1825-1899 гг.) - ученик знаменитого педагога Миланской консерватории Франческо Ламперти (1813-1892 гг.), блистательный певец в молодости, а в зрелые годы - выдающийся педагог. В 1900 г. еще один воспитанник К. Эверарди - Иосиф Гаврилович Супруненко, знаменитый исполнитель партии Германа в «Пиковой даме», открыл свои частные вокальные классы.

Школу К. Эверарди продолжал и ведущий бас одесской сцены Семен Иванович Ильин, обучавшийся у Станислава Ивановича Габеля, в свою очередь, являвшегося воспитанником Франческо Чаффеи и Луиджи Лаблаша. С. Ильин вел класс камерного пения в консерватории, в его классе плодотворно работала концертмейстером ныне заведующая кафедрой общего и специализированного фортепиано профессор Ирина Леонидовна Лисовская.

У Себастьяно Ронкони и Мартина Петца в Италии оттачивала свое вокальное мастерство и выдающийся музыкант, педагог Юлия Александровна Рейдер. Она возглавила вокальное отделение консерватории в трудный предвоенный период 1910-1930 гг. Свой вокально-сценический опыт, традиции итальянской школы Юлия Александровна передала своим ученикам. Ее профессиональные принципы и методы явились краеугольным камнем в строительстве методологической базы, которая в дальнейшем определила педагогическую и исполнительскую практику не одного поколения одесских вокалистов [2, с. 5].

1950-е гг. - период расцвета вокальной кафедры Одесской консерватории. К этому времени достигло профессиональных высот молодое поколение вокалистов, сохранявших бесценные традиции и развивавших педагогические принципы, переданные их учи- 
телями. Эта живительная влага обеспечила не только духовный гомеостаз индивидуума, о котором мы будем говорить ниже, но также и жизнеспособность, уникальное развитие Одесской вокальной школы.

С 1945 г. кафедрой заведует Ольга Николаевна Благовидова, человек высочайшей культуры и профессионализма. В своей педагогической деятельности О. Благовидова наследовала традиции русской и итальянской школ вокального мастерства, составившие органичное единство, а также принципиальную целостность концепции исполнительского мастерства Ю. Рейдер. О. Благовидова формировала профессиональные навыки своих учеников, исходя из позиций комплексного воспитания вокалиста-исполнителя. Ключевой установкой ее педагогических устремлений была «осмысленность звука», что обусловило целый ряд методологических позиций. Из класса этого выдающегося педагога вышла целая плеяда вокалистов, составивших понятие школы Благовидовой (Б. Руденко, Н. Огренич, Т. Мороз и многие другие).

В непосредственной связи с художественными канонами итальянского вокального мастерства формировались педагогические принципы Е. Иванова (как уже было отмечено, учителя В. Навротского).

Е. Иванов окончил класс сольного пения в Харьковском институте искусств у Павла Васильевича Голубева, ученика итальянского певца и вокального педагога Федерико Бугамелли.

П. Голубев придавал первостепенное значение качественной стороне тембра голоса. Соответственно, такие критерии, как сила и диапазон, не являлись главными. Художественная наполненность голоса осознавалась через его тембральную окрашенность. Немаловажной особенностью голоса П. Голубев считал также его природную подвижность и «эластичность». Основополагающий элемент вокальной техники, на котором должны базироваться остальные, - плавное, связное пение - кантилена. Большое значение в школе харьковского педагога придавалось актерскому темпераменту вокалиста, выработке исполнительского эмоционального тонуса и художественной выразительности. Высокое педагогическое мастерство П. Голубева заключалось в комплексном «охвате» проблемы исполнительского мастерства. Он считал, что процесс и методы «подготовки инструмента» заключаются в «параллельном развитии эстетического вкуса в отношении звука, в постепенном расширении возможностей голоса в плане достоверного эмоционального звучания, без утраты необходимых профессиональных качеств и, главное, в развитии интеллекта и культуры» [2, с. 7].

В историю Одесского оперного театра Е. Иванов вошел как выдающийся артист, многие годы украшавший его сцену. Партии Сусанина («Иван Сусанин» М. Глинки), Мельника («Русалка» А. Даргомыжского), князя Галицкого («Князь Игорь» А. Бородина), Карася («Запорожец за Дунаем» С. Гулака-Артемовского), Дона Базилио («Севильский цирюльник» Дж. Россини), Короля Рене («Иоланта» П. Чайковского), Филиппа II («Дон Карлос» Дж. Верди) отличались особой цельностью трактовки, логичностью развертывания музыкально-сценического действия, тонкой, филигранной отделкой музыкального текста, мимики, жеста, движения.

Т. Кнышова рассказывает об удивительных возможностях мастера: «Прекрасная память, позволявшая Е. Иванову разучивать партии, что называется, мгновенно, гибкий и точный интонационный слух, развитый интеллект, - все это определило быстрое, в несколько лет осуществившееся становление его как ведущего солиста Одесского оперного театра. В 23 (!) года он получил звание заслуженного артиста Украины и через несколько лет был приглашен профессором О. Благовидовой, завкафедрой сольного пения Одесской консерватории, на преподавательскую работу в наш вуз» [4, с. 150].

Концерты и спектакли Е. Иванова, человека большой эрудиции и безупречного вкуса, тонкого музыканта становились событиями в музыкальной жизни Одессы. Незабываемое впечатление производили разнообразные камерные программы, исполняемые певцом несколько раз в году.

Певец был великолепным интерпретатором. Известные вокальные произведения звучали в его исполнении удивительно свежо. В каждом из них он находил порой неожиданные, но всегда убедительные, психологически достоверные моменты. Благодаря этому, при абсолютно строгом соблюдении авторского текста, произведение звучало по-новому. В. Навротский вспоминает: «За свою жизнь мне пришлось слышать много интересных исполнителей, которые были достаточно убедительны в своих трактовках. Но, например, «Судьба» С. Рахманинова останется для меня непревзойденным примером исполнения, 
как и большинство обширного камерного репертуара Евгения Николаевича, который он пел в блистательном ансамбле со своей супругой, профессором Людмилой Ильиничной Ивановой» [4, с. 149].

По свидетельству В. Навротского, особым магическим притяжением отличалось великолепное исполнение Е. Ивановым баллад и романсов, вокального цикла «Песни и пляски смерти» М. Мусоргского. Невозможно было забыть четыре образа Смерти, созданные им: «Смерть-успокоительница, Смерть-нянька в «Колыбельной», она же Рыцарь, обольщающий смертельно больную, Смерть-собутыльник в танце-гротеске («Трепак») и Смерть победительница всех и вся в «Полководце» - эти разные обличья одного явления были показаны и спеты Евгением Николаевичем с потрясающей психологической глубиной, с бесконечным разнообразием тембрального и эмоционального наполнения» [4, с. 148].

Остановимся более подробно на особенностях интерпретации этого монументального произведения.

Цикл «Песни и пляски смерти» М. Мусоргского на слова известного поэта и литератора последней трети XIX в. Арсения Аркадиевича Голенищева-Кутузова, его близкого друга и творческого единомышленника, был написан в 1875-1877 гг.

Модест Петрович Мусоргский на стихи А. Голенищева-Кутузова написал также и вокальный цикл «Без солнца» $(1874$ г.), балладу «Забытый» $(1874$ г.), романс «Видение» (1877 г.), либретто оперы «Сорочинская ярмарка». Особенный интерес для многих поколений вокалистов представляет вокальный цикл «Песни и пляски смерти», где показаны поэтизация смерти в символике образов рыцаря, полководца, жанровых танцев и песен (трепак, марш и серенада) и осознание всесильной власти природы и ничтожества сил человеческого тела перед ней.

Этот цикл автор данной статьи начал изучать в классе профессора В. Навротского в ассистентуре-стажировке в 1998 г. Процесс работы над таким сложным и многогранным произведением был трудным и одновременно захватывающим. В те годы Василий Всеволодович был молодым преподавателем, но уже с большим опытом работы на оперной сцене.

Именно это, на наш взгляд, и привнесло новизну, незаангажированность, отсутствие шаблонов в работу В. Навротского как педагога над монументальным, но камерно-философским произведением М. Мусоргского. Здесь хотелось бы привести аналогии с живописью, с живописной текстурой, красками, цветом, светом, бликами светотени, рисующими образы Смерти. Мы как будто видим мать, качающую младенца, кружение снега, поле и одинокого мужичка, пританцовывающего трепака, от одиночества, нужды и безысходности, поле битвы в кроваво-алых бликах и блеск металла. Здесь следует отметить, что А. Голенищев-Кутузов был большим знатоком живописи, собирал, реставрировал картины голландской, нидерландской и итальянской школ. В процессе работы над циклом М. Мусоргский тщательно работал над текстом, изменял, перерабатывал, добиваясь точности и филигранности страшного трагического образа. В. Стасов, который и предложил данную идею, так же предлагал и другие, не вошедшие в цикл темы: Схимник (смерть монаха в келье перед образами, при дальних ударах колокола), изгнанник, тоска и смерть изгнанника, возвращающегося на родину. «Она»- смерть молодой женщины, умирающей, наполняя трагизм ситуации воспоминаниями о любви.

М. Мусоргский ввел в цикл четыре песни: 17 февраля 1875 г. был закончен «Трепак», 14 апреля 1875 г. - «Колыбельная», 11 мая 1875 г. - «Серенада». Заключительная пьеса «Полководец» - лишь через два года, 5 июня 1877 г. Такая очередность дана в редакции Н. Римского-Корсакова, изданной первой после смерти М. Мусоргского. Здесь хотелось бы добавить, что Стасов предложил идею создания произведения, подобного «Пляске смерти» Ф. Листа, такую «Русскую пляску смерти». Четырем пьесам цикла композитор сделал посвящения: «Колыбельная» - А. Воробьевой-Петровой, «Серенада» - Л. Глинке-Шестаковой, «Трепак» - знаменитому русскому басу О. Петрову, «Полководец» - А. Голенищеву-Кутузову. Детализируя, добавим, что композитор не только посвятил, но и тонко в аккомпанементе, а главное, в вокальной партии выдерживал тесситуру вокалиста («диапазон контральто» в «Колыбельной» для певицы А. Воробьевой, в «Полководце» - диапазон меццо-сопрано). Для практического исполнения требуется транспозиция. В. Навротский как педагог опирался в нашем обучении на «плечи Титанов»: исполнение и трактовку своего учителя, профессора Е. Иванова, но также привнес много нового: собственное, уникальное понимание и характерные особенности интерпретации данного цикла.

В этот общий сюжет М. Мусоргский вложил всю чуткость и боль человека перед трагизмом человеческого ухода, страдания духа и тела. На наш взгляд, интерес и новизна 
педагогической интерпретации Василия Всеволодовича Навротского заключаются в его очень необычной, уникальной трактовке образа смерти. Он предложил не столько представить его фантастико-трагедийным в своей жуткой реальности, а попытаться представить смерть разрушением духовного гомеостаза (Парацельс), разрушением состояния гармонии между Внутренним и Внешним мирами, приблизить этот образ к человеческому бытию, как бы «тонко упростить». Нет гомеостаза, прервалось выделение человеком энергии, - наступила смерть [8, с. 413].

Педагог убеждал, что необходимо упростить осмысление и восприятие философского образа смерти, но при этом музыкальная канва цикла представляет собой сконцентрированно-драматические сцены с симфонически-напряженным развитием: экспозицию, противостоящие и противоборствующие темы, кульминацию их развития, разрешающий эпилог. Новизна такого подхода в педагогической практике очевидна. Здесь хочется акцентировать внимание на бесценном эмпирическом опыте педагога, который часто опережает теоретическую мысль, передавая свои гипотезы, находки, обобщения, а главное - исполнительское мастерство, звучание голоса!

Хочется затронуть и процесс подготовки к изучению цикла, как одну из главных составляющих педагогического плана, его действа. Перед тем как приступить к изучению произведения, В. Навротский требовал настоятельно изучить информационную сферу поэтического текста, вплоть до итальянской терминологии, ремарок композитора, определив действенные пружины драматургии, вплоть до знаков пунктуации, произношения правильного красивого русского слова.

Вторым этапом он выделил ассоциации, их связи с поэтическим словом: ассоциации, возникающие при изучении музыкального текста, фразеологии ключевых нот, их значение или личностные гипотезы их значения, чтобы ничего не стало проходящим, мимоходным.

Третьим этапом была работа над контрастностью, тембральной, штриховой, даже контрастностью пауз, которые «должны жить». Наполнена такого рода паузами «Колыбельная» и заключительный «Полководец», где паузы ни в коем случае не должны переключать действие, а рваные фразы, как «клочья разорванных тел». Еще одной интересной особенностью нашей работы над циклом было то, что Василий Всеволодович имел особый вариант трактовки танца: экстраполировав жанровый танец украинского фольклора «гопак» и русский «трепак», и, повторюсь, «тонко упростив» саркастическую грань человеческой сути. Приведем определение данных танцев в «Словаре русского языка» С. Ожегова: «гопак - украинская народная пляска, а также музыка к ней» [5, с. 124]; «трепак - русский народный танец с сильным притопыванием» [5, с. 719].

В работе над циклом В. Навротский обращал внимание на трансформацию пляски, которая являлась и символикой, и самим образом, и рефреном образа смерти. От Трепака в первой части пьяненького мужичка до «пляской притопчу» в alla Marcia в «Полководце» в Grave pomposo. Опять же «упростить», но спеть как тяжелый марш.

Важной составляющей в работе над циклом стало требование педагога-вокалиста о рациональном распределении вокальных ресурсов, особенно в заключительном произведении цикла на буквально могучей мелодии, переработанной М. Мусоргским польской революционной песни «С дымом пожаров». Часто В. Навротский говорил о необходимости очертить тембрально кульминационные точки частей цикла.

Например, в «Серенаде», где фортепиано имитирует гитарный аккомпанемент, торжествующее восклицание «Ты - моя!» спеть с лукавой хитрецой и лишь в самом конце, почти на кульминационной интонации выложить торжество смертельного страха и смертельной победы!

Особенное внимание уделялось музыкальной терминологии, использованной в цикле «Песни и пляски смерти». Приведем некоторые термины:

1. Lento doloroso - медленно с болью.

2. Agitato pathetico - взволнованно с патетикой.

3. Lento funesto - медленно с гибелью.

4. Poco capriccioso - немного капризно.

5. Parlando - проговаривая.

6. Ancora piu sostenuto - еще более сдержанно.

7. Tempo di Marcia - в темпе марша.

8. Grave - тяжело.

9. Pomposo - напыщенно [7]. 
Точное понимание значения данных определений помогало в правильной трактовке сложных образов цикла.

Выводы. В современной практике Одесской вокальной школы сохраняется преемственность важнейших исполнительских и педагогических принципов. Основные принципы обучения, заложенные Е. Ивановым, сохраняются и составляют истоки профессионализма и исполнительского интеллекта В. Навротского. Рассмотренная самобытная интерпретация В. Навротским вокального цикла «Песни и пляски смерти» М. Мусоргского чрезвычайно актуальна и представляет несомненный интерес. Одной из важнейших дидактических задач при изучении данного цикла становится формирование в единой совокупности профессиональных навыков, а также образно-содержательных и эмоционально-художественных задач музыкального текста. В философской трактовке смерти В. Навротский предлагает исполнителю не создать фантастико-трагедийный в своей жуткой реальности образ, а попытаться представить смерть разрушением духовного гомеостаза (Парацельс), разрушением состояния гармонии между Внутренним и Внешним мирами, приблизить этот образ к человеческому бытию, как бы «тонко упростить». Многогранность исполнительских и педагогических подходов в интерпретации вокального цикла «Песни и пляски смерти» М. Мусоргского способствует целостному формированию сложных образов этого произведения.

\section{СПИСОК ЛИТЕРАТУРЫ}

1. Львов М. Антонина Васильева Нежданова. Опыт творческой характеристики. Москва : Музгиз, 1946. 212 с.

2. Навротский В. Педагогические принципы одесской вокальной школы. Одесская вокальная школа; истоки и вершины : учебное пособие. Рукопись. 2003-2010. 124 с.

3. Огренич Н. Твои имена, Одесса... Одесса: Астропринт, 2003. Кн. 5. 605 с.

4. Одесская консерватория: Забытые имена, новые страницы / Одесская государственная консерватория им. А. В. Неждановой / гл. ред. Н. Огренич. Одесса : ОКФА, 1994. 248 с.

5. Ожегов С. Словарь русского языка / ред. Н. Шведовой. 14-е изд., стереотип. Москва : Рус. яз., 1983. 816 с.

6. Руффо Т. Парабола моей жизни. Москва : Музыка,1966. 436 с.

7. Словарь иностранных музыкальных терминов. 7-е изд. Ленинград : Музыка, 1988. 136 с.

8. Философский словарь / под ред. И. Фролова. 6-е изд., перераб., доп. Москва : Политиздат, 1991. $560 \mathrm{c}$.

\section{REFERENCES}

1. Lvov, M. (1946). Antonina Vasilyevna Nezhdanova. Experience of the creative specifications. Moscow: Muzgiz [in Russian].

2. Navrotskiy, V. V. (2003-2010). The pedagogical principles of the Odessa vocal school. Odessa vocal school; roots and tops: a tutorial. Manuscript [in Russian].

3. Ogrenich, N.G. (2003). Your names, Odessa ... Vol. 5. Odessa: Astroprint [in Russian].

4. Odessa Conservatory: Forgotten Names, New Pages (1994). Odessa state Conservatory named after A.V. Nezhdanova / ch. ed. N.L. Ogrenich. Odessa: OKFA [in Russian].

5. Ozhegov, S.I. (1983). Dictionary of the Russian language. Ed. N.Yu. Shvedova; ed. 14th, stereotype. Moscow: Rus. yaz. [in Russian].

6. Ruffo, T. (1966). The parabola of my life. Moscow: Muzyka [in Russian].

7. Dictionary of foreign musical terms (1988). 7-th ed. L.: Muzyka [in Russian].

8. Philosophical Dictionary (1991). Ed. I.T. Frolov; 6-th ed., Revised., Ext. Moscow: Politizdat [in Russian]. 